\title{
Factors associated with contraceptive use among sexually active Nepalese youths in the Kathmandu Valley
}

\author{
Laxmi Tamang $^{1^{*}}$ (D), Camille Raynes-Greenow ${ }^{2}$, Kevin McGeechan ${ }^{2}$ and Kirsten Black ${ }^{3}$
}

\begin{abstract}
Background: In Nepal, evidence is sparse regarding the use of contraception at first and current relationships among sexually active young people. This study examined the factors associated with modern contraceptive use at first and current sexual relationships.

Methods: A descriptive cross-sectional household survey conducted amongst young Nepalese men and women living in the urban areas of the Kathmandu valley. We used logistic regression to model the relationship between selected independent variables and outcome variables (use at first sexual intercourse and current use of modern contraception) among 492 ever sexually active youth aged 15-24 years.

Results: We found that the key factors associated with current non-use of modern contraceptives among sexually active youth age 15-24 were young age at first sexual contact and a relationship with someone other than a spouse, while significant factor associated with current use of contraception was religion, revealing that Hindu youths having lower odds of use compared to young people who belonged to other religions.

Conclusions: The findings suggest that contraception education should be intensified and directly towards those entering adolescence to encourage youths to adopt contraception at the time of their first sexual relationship. The influence of religion on use of modern contraception needs further exploration.
\end{abstract}

Keywords: Contraceptive, Nepal, Young people

\section{Background}

Access to safe and effective contraception is essential for optimal sexual and reproductive health $[1,2]$ and allows for the prevention of unintended pregnancies, improved pregnancy spacing and reduced transmission of sexually transmitted infections and HIV [3-5]. Although overall contraceptive use has increased worldwide, youth access to sexual and reproductive health services and comprehensive sexuality education, that are high-quality, youthfriendly and respect the right to confidentiality, privacy and informed consent remains a challenge in many countries [6-8]. Globally, from a public health perspective there is a widening gap between sexual debut and age of marriage, and increased sexual activity prior to

\footnotetext{
* Correspondence: laxtshering@yahoo.com

${ }^{1}$ APS Prasuti Tatha Prajanan Swasthya Kendra, Link Marg 1045, Kuleshwor,

Kathmandu, Nepal

Full list of author information is available at the end of the article
}

marriage [9], which exposes young people to the risk of unplanned pregnancy [10-12].

The few studies that have been conducted in Nepal on young peoples' sexual behaviour have found that they experience a wide range of consensual and coercive sexual relationships and that the proportion of sexually experienced unmarried young people is rising [7, 13-17]. Early sexual experimentation, combined with low and irregular use of condoms in Nepalese society places young people at risk of HIV and other sexually transmitted infection [7, 13, 15-17]. Indeed the Nepal Adolescent and Youth Survey 2010/2011 reported that one in six young people aged 15-24 had been involved in risky sexual practices such as oral, anal and paid sex and almost $13 \%$ had premarital sex, of which only $46 \%$ had used contraception at the time of their first sexual intercourse [15]. The same study revealed that almost one-fifth of young people had their first sexual intercourse unwillingly and forcefully. 
As well as being exposed to sexually transmitted infections, unsafe sex exposes young people to the risk of unplanned pregnancy. Across South Asia the uptake of modern contraceptive methods amongst sexually active young people has been poor and early childbearing is common $[9,18]$. This is true of women in Nepal where almost one quarter of women give birth by age 18 and nearly half by age 20 [17]. While use of any contraceptive method, including modern contraceptive methods by reproductive aged women married or in a union, is around the average for South Asian countries at 49\%, the incidence of unintended pregnancy is higher in Nepalese adolescents (32\%) [19]. Furthermore, the 2011 Nepal Demographic Health Survey reported that unmet need for contraception is particularly high among young women aged $15-19$ and $20-24$, at $41 \%$ and $37 \%$ respectively compared to women in older age groups $30 \%$ or less.

In Nepal, family planning being one of the priority programs of the government modern contraceptive methods both short-acting and long acting reversible contraceptive services are freely available to all reproductive age men and women through public health system. The main aim of the national family planning program is to ensure that individuals and couples are able to fulfil their reproductive needs by using appropriate contraceptive methods based on informed choice.

Following the International Conference on Population and Development held in Cairo in 1994, the government of Nepal committed to promoting and protecting the sexual and reproductive rights of adolescents and youth [20]. Collaborating with national and international agencies the Nepalese government is striving to achieve the development goals that place considerable importance on increasing the use of contraception and reducing the fertility rate, as well as to address gender inequality and women's empowerment [21]. Understanding the key factors influencing contraceptive use among young sexually active youths who are at risk of unwanted pregnancies is key to the development of effective family planning programs. This study aims to examine the factors associated with contraceptive use at the first sexual intercourse and current relationships among Nepalese youth living in urban areas of the Kathmandu Valley.

\section{Methods}

\section{Study setting and design}

The data were collected from a field survey conducted in the urban areas of the Kathmandu Valley, comprising all five major cities: Kathmandu metropolitan city, Lalitpur sub-metropolitan city, Bhaktapur municipality, Kirtipur municipality, and Thimi municipality. The study was part of a larger study that employed mix-methods, and comprised a household survey, focus group discussions and in-depth interviews aiming to investigate how gendered power relations influence knowledge of SRH and access to, and utilisation of, SRH services among youth in the Kathmandu valley, Nepal. In this paper we present the cross-sectional household survey information. The data were collected using two-stage cluster sampling from the study area. In the first stage of sample selection, primary sampling units (clusters i.e. wards) were selected using a probability proportional-to-size from each study area. We randomly selected a total of 40 clusters from three district urban areas using household and population information from the 2011 Population Census developed by the Central Bureau of Statistics. In the second stage, 35 households in each cluster were selected using a systematic sampling technique. Thus, we needed to visit a total of 1400 households in order to interview the required number of youths.

\section{Study population}

This study was part of the large study among youth thus information was collected from 1400 urban youths, comprising 720 females and 680 males. The sample size for the study was calculated based on the $50 \%$ prevalence of young Nepalese women aged 15-24 who had ever had sexual intercourse with 95\% confidence intervals, $5 \%$ margin of error, 1.6 design effect obtained from those who had had sexual intercourse before age 18 and $10 \%$ none response rate $[15,17]$. However, for the purpose of this paper only 492 young men and women who had prior sexual experience were included to examine the use of contraceptives at their first and current sexual relationships.

\section{Questionnaire}

The questionnaire consisted of standard items that were adapted from previous studies and validated in similar settings including questions from the Nepal Demographic Health Surveys [15, 22-25]. Some items were modified and added to the questionnaire to suit the context of the study. The questionnaire was finalised after pilot-testing outside the study areas.

Two questionnaires were administered: the household questionnaire and the individual questionnaire. The household questionnaires were used to list all the usual members in the selected households and gathered basic information about the household and characteristics of individuals living there. The individual questionnaire was administered to all youth aged $15-24$ by trained female research assistants. The respondents were interviewed face-to-face and provided with an explanation for question items.

\section{Measures}

Respondents were asked if they had ever had engaged in sexual intercourse in their life to ensure they met the 
"sexually active" requirement for participation in the study. Any participant who answered "no" was not eligible for participation in the study. Lastly, participants were asked if they were currently involved in a relationship where they had regularly have sexual intercourse, and if they answered yes, they were further asked to indicate the length of this relationship.

\section{Analysis}

We applied both univariate and multivariable analyses in this study to examine the association between each of the outcome variables, 'use of modern contraceptive method at the first sexual contact' and 'current use of contraceptive', and he explanatory variables sex, age, marital status, place of origin, education, ethnicity, religion, occupation, source of income, age at the first sexual intercourse, relationship type, method of participation in the first sexual intercourse, ever discussed about the importance of safe sex with partner, ever had discussed of contraceptive use with partner, and the main source of sexual and reproductive information among sexually active youths who were not planning to have a baby [21, 26-28]. A dichotomous measure indicated whether respondents had used any modern method contraception the first time they had intercourse and whether they were currently using contraceptives. We used the IBM Statistical Package for the Social Sciences (SPSS) software Version 16 (SPSS Inc., Chicago, IL, USA) complex samples procedures to account for the sampling design in the calculation of the association measures. The level of statistical significance was set at a level of $p<0.05$.

\section{Ethical approval}

Ethical approval was granted by the University of Sydney's Human Research Ethics Committee and from the Nepal Health Research Council. Informed consent from each study participant was obtained after clear explanation about the purpose of the study. A written informed consent sheet was prepared for the parents or legal guardians of participants less than 16 years to give their signed consent on behalf of their children. The study participants and parents or legal guardians were informed that they had full right to withdraw from the study. Confidentiality of the information was assured by omitting names of study participants from the questionnaire and respondents were interviewed in a separate place to maintain their privacy.

\section{Results}

\section{Socio-demographic characteristics}

Of the total 492 sexually active young men and women, the majority of there were aged 20-24 (77\% men and $79 \%$ women), had never been married (13\% men and $95 \%$ women), were urban in origin (56\% men and $64 \%$ women), and had ever studied at school (98\% men and $92 \%$ women) women (Table 1). Most of them had the School Leaving Certificate (SLC) or above level of education ( $84 \%$ men and $48 \%$ women). More than half were Indo-Aryan by ethnicity (57\% men and $56 \%$ women) and most were Hindu (79\% men and $83 \%$ women). Men were significantly more likely than women not to be married $(p<0.001)$, ever studied at school $(p=0.011)$, have obtained a degree in higher education $(p<0.001)$, were students $(p<0.001)$, selfdependent for income $(p=0.011)$, had relationship with girlfriends $(p<0.001)$, participated willingly in a sexual activity $(p<0.001)$, had two or more sexual partners in their life time $(p<0.001)$, ever discussed of contraceptive use $(p=0.002)$ and radio was their major source of SRH information $(p=0.002)$.

\section{Contraceptive methods used at first sex and in current relationship}

Half of ever sexually active young people who were not planning a pregnancy had used a modern method of contraception at the time of their first sexual intercourse and of these, the majority (48\%) had used condoms (Table 2). Condoms were also the most commonly used method amongst currently sexually active youth, with $66 \%$ of participants using a modern contraceptive method: $39 \%$ were using condoms followed by $28 \%$ injectables and $8 \%$ the oral contraceptive pill.

\section{Determinants of contraceptive use}

Use at first sexual intercourse: Seventy percent of males and $31 \%$ of females used modern contraceptive methods at their first sexual intercourse. The factors statistically associated with contraceptive use at first sexual intercourse were sex of participant, whether or not they had ever studied at school, age at first sexual intercourse and type of relationship (Table 3 ). The analysis suggests that compared to females, males had a 5.14 times greater odds of reporting use of contraception in their first sexual contact. Greater odds of contraceptive use were also associated with ever having studies at school, and having a relationship with a person other than a spouse. Those who had their first sexual encounter between the ages of $12-15$ had significantly lower odds of having used contraception compared to women whose first sex occurred between 16 and 19 or 20 and 24 years. In the multivariable analysis only age at first sexual intercourse and relationship type with partner remained significant (Table 3 ).

Current use: Among young people not wanting to conceive, univariate analysis revealed greater odds of current use of contraception amongst males compared to females and amongst non-Hindus (Table 4). In the adjusted multivariate logistic we included all the 
Table 1 Socio-demographic characteristics of young people aged 15-24 by sex

\begin{tabular}{lllll}
\hline $\begin{array}{l}\text { Background } \\
\text { Characteristics }\end{array}$ & All & Male & Female & $P$ value \\
& $(n=492)$ & $(n=247)$ & $(n=245)$ & \\
& No. (\%) & No. (\%) & No. (\%) & \\
\hline
\end{tabular}

Age (in years):

$\begin{array}{lllll}15-19 & 108 & 57(23.0) & 51(20.7) & 0.605 \\ 20-24 & 384 & 190(77.0) & 194(79.3) & \end{array}$

Marital Status:

$\begin{array}{lllll}\text { Ever married } & 265 & 33(13.4) & 233(95.0) & <0.001^{*} \\ \text { Never married } & 226 & 214(86.6) & 12(5.0)\end{array}$

Place of origin:

$\begin{array}{lllll}\text { Rural } & 296 & 139(56.3) & 157(64.2) & 0.187 \\ \text { Urban } & 196 & 108(43.7) & 88(35.8) & \end{array}$

Ever studied at school:

$\begin{array}{ll}\text { Yes } & 469 \\ \text { No } & 23\end{array}$

Education:

$\begin{array}{lcccc}\begin{array}{l}\text { Some secondary } \\ \text { and below }\end{array} & 168 & 41(16.4) & 127(52.0) & <0.001^{*} \\ \text { SLC and above } & 324 & 206(83.6) & 118(48.0)\end{array}$

Ethnicity:

$\begin{array}{lllll}\text { Tibeto-Burmese } & 214 & 106(42.9) & 108(44.3) & 0.799 \\ \text { Indo-Aryan } & 278 & 141(57.1) & 137(55.7) & \\ \text { Religion: } & & & & \end{array}$

\begin{tabular}{|c|c|c|c|c|}
\hline Hindu & 400 & $197(79.6)$ & $203(83.1)$ & 0.408 \\
\hline Non-Hindu ${ }^{b}$ & 92 & $50(20.4)$ & $42(16.9)$ & \\
\hline \multicolumn{5}{|l|}{ Occupation: } \\
\hline Non-students & 277 & $74(29.7)$ & $203(83.1)$ & $<0.001^{*}$ \\
\hline Students & 215 & $173(70.3)$ & $42(16.9)$ & \\
\hline \multicolumn{5}{|l|}{ Source of income: } \\
\hline Parents and others & 432 & $205(83.1)$ & 227 (92.6) & $0.012^{*}$ \\
\hline Self & 60 & $42(16.9)$ & $18(7.4)$ & \\
\hline
\end{tabular}

Age at the first sexual intercourse

$\begin{array}{llll}12-15 & 42 & 20(8.0) & 22(9.1) \\ 16-19 & 306 & 165(67.1) & 141(57.5) \\ 20-24 & 144 & 62(25.0) & 82(33.4)\end{array}$

Relationship type

$\begin{array}{lllll}\text { Spouse } & 255 & 22(8.8) & 233(95.0) & \\ \text { Boy/girlfriend } & 215 & 205(82.9) & 10(4.3) & <0.001^{*} \\ \begin{array}{l}\text { Familiar person/ } \\ \text { sex worker }\end{array} & 22 & 20(8.3) & 2(0.7) & \\ \begin{array}{l}\text { Type of participation } \\ \text { Willingly }\end{array} & & & & \\ \text { Unwillingly/forcefully } & 35 & 6(2.3) & 29(11.7) & \end{array}$

Table 1 Socio-demographic characteristics of young people aged $15-24$ by sex (Continued)

\begin{tabular}{lcclll}
\hline No. of sexual partners in life time & & & \\
One & 451 & $107(43.1)$ & $244(99.7)$ & $<0.001^{*}$ \\
Two and more & 141 & $140(56.9)$ & $1(0.3)$ & \\
Ever discussed of safe sex with partner & & & \\
No & 120 & $50(20.3)$ & $70(28.4)$ & 0.100 \\
Yes & 372 & $197(79.7)$ & $175(71.6)$ &
\end{tabular}

Ever discussed of contraceptive use

$\begin{array}{lllll}\text { No } & 68 & 20(8.2) & 48(19.6) & 0.002^{*} \\ \text { Yes } & 424 & 227(91.8) & 197(80.4) & \end{array}$

Source of SRH information

$\begin{array}{lllll}\text { Radio } & 391 & 212(85.9) & 178(72.9) & 0.002^{*} \\ \text { Television } & 70 & 26(10.7) & 44(17.9) & \\ \begin{array}{l}\text { Friends, teachers } \\ \text { and others }\end{array} & 31 & 8(3.4) & 23(9.3)\end{array}$

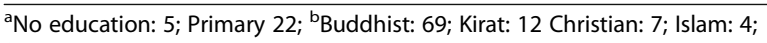

CFamiliar person: 19 , Sex worker: $7 ;{ }^{*} P<0.05$

variables with a $p$-value less than 0.25 in the univariate analysis that comprised sex, age, place of origin, religion, source of income and ever discussed about safer sex. The only significant association that remained after multivariable logistic regression analysis was with religion

Table 2 Percentage distributions of modern contraceptive use and method mix at first sexual relationship and current use among sexually active young people in the Kathmandu valley

\begin{tabular}{|c|c|c|c|}
\hline Contraceptive method mix & $\mathrm{n}^{\mathrm{a}}$ & Percent & $\begin{array}{l}\text { 95\% Confidence } \\
\text { Interval }\end{array}$ \\
\hline \multicolumn{4}{|l|}{ Used at first sexual intercourse } \\
\hline Traditional method users & 38 & 7.7 & $4.7-12.4$ \\
\hline Non-users & 206 & 41.9 & $35.9-48.0$ \\
\hline Any modern method users & 248 & 50.4 & $45.0-55.8$ \\
\hline Condom & 235 & 47.7 & $42.4-53.1$ \\
\hline Pill ${ }^{b}$ & 12 & 2.5 & $1.4-4.4$ \\
\hline Injectables & 1 & 0.2 & $0-2.5$ \\
\hline Total & 492 & 100.0 & - \\
\hline \multicolumn{4}{|l|}{ Current use of contraception } \\
\hline Traditional method users & 40 & 20.8 & $16.0-26.5$ \\
\hline Non-users & 26 & 13.0 & $8.6-19.4$ \\
\hline Any modern method users & 129 & 66.2 & $59.7-72.1$ \\
\hline Condom & 77 & 39.4 & $32.1-47.2$ \\
\hline Pill & 10 & 4.9 & $2.6-8.8$ \\
\hline Injectables & 36 & 18.7 & $13.6-25.2$ \\
\hline IUCD/Implants ${ }^{\mathrm{c}}$ & 4 & 2.1 & $0.7-6.4$ \\
\hline Sterilisation & 2 & 1.1 & $0.3-3.4$ \\
\hline Total & 195 & 100.0 & - \\
\hline
\end{tabular}

${ }^{a}$ Weighted samples to represent population; ${ }^{b}$ Emergency Contraceptive: $2 ;{ }^{c} 2$ each 
Table 3 Factors associated with use of modern contraception at first sexual intercourse among sexually active Nepalese youth, univariate and multivariate analyses

\begin{tabular}{|c|c|c|c|c|c|c|}
\hline \multirow[t]{2}{*}{ Background Characteristics } & \multirow[t]{2}{*}{$\mathrm{n}=492(\%)$} & \multirow{2}{*}{$\begin{array}{l}\% \text { of youth used modern } \\
\text { contraceptive methods }\end{array}$} & \multicolumn{2}{|l|}{ Univariate analyses } & \multicolumn{2}{|l|}{ Multivariate analyses } \\
\hline & & & $\begin{array}{l}\text { Odd ratio } \\
(95 \% \mathrm{Cl})\end{array}$ & $p$-value & $\begin{array}{l}\text { Adjusted odd ratio } \\
(95 \% \mathrm{Cl})\end{array}$ & $p$-value \\
\hline \multicolumn{7}{|l|}{ Sex } \\
\hline Female & $245(49.8)$ & $76(30.9)$ & Ref. & $<0.001^{*}$ & Ref. & 0.437 \\
\hline Male & $247(50.2)$ & $172(69.7)$ & $5.14(3.34-7.89)$ & & $1.48(0.54-4.03)$ & \\
\hline \multicolumn{7}{|l|}{ Place of origin } \\
\hline Rural & $296(60.2)$ & $141(47.6)$ & Ref. & & Ref. & 0.849 \\
\hline Urban & $196(39.8)$ & $107(54.6)$ & $1.32(0.92-1.90)$ & 0.128 & $0.96(0.64-1.45)$ & \\
\hline \multicolumn{7}{|l|}{ Ever studied at school } \\
\hline Yes & $469(95.3)$ & $245(52.2)$ & $6.51(1.51-28.08)$ & $0.013^{*}$ & $2.74(0.74-10.21)$ & 0.128 \\
\hline No & $23(4.7)$ & $3(14.4)$ & Ref. & & Ref. & \\
\hline \multicolumn{7}{|l|}{ Ethnicity } \\
\hline Tibeto-Burmese & $214(43.6)$ & $103(41.6)$ & Ref. & 0.363 & Ref. & 0.486 \\
\hline Indo-Aryan & $278(56.4)$ & $145(58.4)$ & $1.18(0.82-1.69)$ & & $1.17(0.74-1.85)$ & \\
\hline \multicolumn{7}{|l|}{ Religion } \\
\hline Hindu & $400(81.3)$ & $204(82.1)$ & Ref. & 0.671 & Ref. & 0.860 \\
\hline Non-Hindu ${ }^{a}$ & $92(18.7)$ & $44(17.9)$ & $0.91(0.91-1.45)$ & & $0.95(0.54-1.68)$ & \\
\hline \multicolumn{7}{|l|}{ Age at the first sexual intercourse } \\
\hline $12-15$ & $42(8.5)$ & $7(2.6)$ & $0.17(0.07-0.41)$ & $0.001^{*}$ & $0.10(0.03-0.31)$ & $0.001^{*}$ \\
\hline $16-19$ & $306(62.3)$ & $167(67.5)$ & $1.13(0.72-1.76)$ & & $0.81(0.50-1.33)$ & \\
\hline $20-24$ & $144(29.2)$ & $74(29.9)$ & Ref. & & Ref. & \\
\hline \multicolumn{7}{|l|}{ Relationship type with partner } \\
\hline Spouse & $255(51.7)$ & $76(30.6)$ & Ref. & $<0.001^{*}$ & Ref. & $0.003^{*}$ \\
\hline Boy/girlfriend & $215(43.8)$ & $153(61.7)$ & $5.78(3.88-8.61)$ & & $4.55(1.63-12.75)$ & \\
\hline Familiar person/sex worker ${ }^{\mathrm{b}}$ & $22(4.5)$ & $19(7.7)$ & $15.29(4.88-47.89)$ & & $11.85(2.70-43.54)$ & \\
\hline \multicolumn{7}{|l|}{ Type of participation } \\
\hline Willingly & $458(93.0)$ & $236(95.1)$ & Ref. & 0.064 & Ref. & 0.826 \\
\hline Unwillingly/forcefully & $34(7.0)$ & $12(4.9)$ & $0.51(0.25-1.04)$ & & $0.92(0.44-1.95)$ & \\
\hline Total & - & $248(50.4)$ & & & & \\
\hline
\end{tabular}

${ }^{\mathrm{a} B u d d h i s t: ~ 69, ~ K i r a t: ~ 12, ~ C h r i s t i a n: ~ 7, ~ I s l a m: ~ 4 ; ~}{ }^{\mathrm{b}}$ Familiar person: 19, Sex worker: 7; Cl: Confidence Interval; Ref: Reference category; ${ }^{*} p<0.05$

and current use of contraception, such that young people who belong to non-Hindu religious group had 3.24 (95\% CI: 1.39-7.56; $p=0.008$ ) times greater odds of using modern contraception compared to young people who stated they were Hindu.

\section{Discussion}

This study examined the timing, circumstances and use of modern contraception among sexually active youth aged 15-24 living in urban area of the Kathmandu Valley at their first and in their current sexual relationship. We found that half of young people had used a modern method of contraception at first intercourse and over two thirds in their current relationships and in both circumstances condoms were the most frequently used method followed by the oral contraceptive pill and injectables. These findings are similar to those in the 2011 National Adolescents and Youth Survey figures that revealed $46 \%$ of young people had used contraception at the time of their first sexual intercourse and of those, $91 \%$ of them used condoms, three precent the oral contraceptive pill, and one percent the injection [15]. This may relate to the fact that government of Nepal has made these methods easily available and accessible to all reproductive age men and women in Nepal. As a policy measure, findings of this study are very useful as it can inform policy and decision making in the government healthcare system to increase the contraception users among youth to 
Table 4 Results of univariate and multivariate analyses for current use of contraception among sexually active Nepalese youths

\begin{tabular}{|c|c|c|c|c|c|c|}
\hline \multirow[t]{2}{*}{ Background Characteristics } & \multirow[t]{2}{*}{$\mathrm{n}=195(\%)$} & \multirow{2}{*}{$\begin{array}{l}\% \text { of youth currently using } \\
\text { modern contraceptive }\end{array}$} & \multicolumn{2}{|l|}{ Univariate analyses } & \multicolumn{2}{|c|}{ Multivariate analyses } \\
\hline & & & Odd ratio/Cl & $\overline{p \text {-value }}$ & $\begin{array}{l}\text { Adjusted odd } \\
\text { ratio }(95 \% \mathrm{Cl})\end{array}$ & $p$-value \\
\hline \multicolumn{7}{|l|}{ Sex: } \\
\hline Female & $151(77.3)$ & $94(62.4)$ & Ref. & $0.043^{*}$ & Ref. & 0.232 \\
\hline Male & $44(22.7)$ & $35(79.0)$ & $2.27(1.03-5.03)$ & & $1.62(0.73-3.61)$ & \\
\hline \multicolumn{7}{|l|}{ Age (in years): } \\
\hline $15-19$ & $29(14.7)$ & $16(55.3)$ & $0.58(0.25-1.34)$ & 0.195 & $0.63(0.26-1.51)$ & 0.287 \\
\hline $20-24$ & $166(85.3)$ & $113(68.0)$ & Ref. & & Ref. & \\
\hline \multicolumn{7}{|l|}{ Marital Status: } \\
\hline Ever married & $160(82.1)$ & $104(65.2)$ & Ref. & 0.487 & - & - \\
\hline Never married & $35(17.9)$ & $25(70.7)$ & $1.29(0.62-2.68)$ & & & \\
\hline \multicolumn{7}{|l|}{ Place of origin: } \\
\hline Rural & $122(62.8)$ & $76(62.1)$ & Ref. & 0.154 & Ref. & 0.087 \\
\hline Urban & $73(37.2)$ & $53(73.0)$ & $1.64(0.82-3.29)$ & & $1.87(0.91-3.83)$ & \\
\hline \multicolumn{7}{|l|}{ Education: } \\
\hline Some secondary and below ${ }^{a}$ & $82(41.9)$ & $54(65.7)$ & Ref. & 0.927 & - & - \\
\hline SLC and above & $113(58.1)$ & $75(66.4)$ & $1.03(0.52-2.05)$ & & & \\
\hline \multicolumn{7}{|l|}{ Ethnicity: } \\
\hline Tibeto-Burmese & $90(45.9)$ & $59(66.0)$ & Ref. & 0.963 & - & - \\
\hline Indo-Aryan & $105(54.1)$ & $70(66.3)$ & $1.01(0.60-1.69)$ & & & \\
\hline \multicolumn{7}{|l|}{ Religion: } \\
\hline Hindu & 159 (81.6) & $99(61.9)$ & Ref. & $0.007^{*}$ & Ref. & $0.008^{*}$ \\
\hline Non-Hindu ${ }^{b}$ & $36(18.4)$ & $30(85.0)$ & $3.49(1.43-8.49)$ & & $3.24(1.39-7.56)$ & \\
\hline \multicolumn{7}{|l|}{ Occupation: } \\
\hline Non-students & $139(71.4)$ & $93(66.9)$ & Ref. & 0.663 & & \\
\hline Students & $56(28.6)$ & $36(64.3)$ & $0.89(0.53-1.50)$ & & & \\
\hline \multicolumn{7}{|l|}{ Source of income: } \\
\hline Parents and others & $179(92.1)$ & $116(64.6)$ & Ref. & 0.081 & Ref. & 0.209 \\
\hline Self & $16(7.9)$ & $13(84.5)$ & $2.99(0.97-10.34)$ & & $2.18(0.63-7.53)$ & \\
\hline \multicolumn{7}{|l|}{ Age at the first sexual intercourse } \\
\hline $12-15$ & $19(9.4)$ & $11(60.3)$ & $0.61(0.18-2.02)$ & 0.582 & - & - \\
\hline $16-19$ & $106(54.5)$ & $68(63.7)$ & $0.70(0.34-1.43)$ & & & \\
\hline $20-24$ & $70(36.1)$ & $50(71.4)$ & Ref. & & & \\
\hline \multicolumn{7}{|l|}{ Relationship type } \\
\hline Spouse & $158(81.3)$ & $103(64.8)$ & Ref. & & - & - \\
\hline Boy/girlfriend or causal partner ${ }^{c}$ & $37(18.7)$ & $26(71.9)$ & $1.39(0.69-2.81)$ & 0.348 & & \\
\hline \multicolumn{7}{|l|}{ No. of sexual partners in life time } \\
\hline One & $170(87.5)$ & $113(66.4)$ & Ref. & 0.871 & - & - \\
\hline Two and more & $24(12.5)$ & $16(64.7)$ & $0.93(0.37-2.32)$ & & & \\
\hline \multicolumn{7}{|l|}{ Ever discussed of safe sex with partner } \\
\hline No & $37(19.1)$ & $21(55.6)$ & Ref. & 0.111 & Ref. & 0.444 \\
\hline Yes & $158(80.9)$ & $108(68.7)$ & $1.75(0.87-3.50)$ & & $1.34(0.62-2.88)$ & \\
\hline
\end{tabular}


Table 4 Results of univariate and multivariate analyses for current use of contraception among sexually active Nepalese youths (Continued)

\begin{tabular}{lllll}
\hline $\begin{array}{l}\text { Ever discussed of contraceptive use } \\
\text { No }\end{array}$ & $21(10.6)$ & $14(69.1)$ & Ref. & 0.720 \\
Yes & $174(89.4)$ & $115(65.8)$ & $0.86(0.37-2.01)$ & \\
Source of SRH information & & & Ref. & 0.858 \\
$\quad$ Radio & $148(76.1)$ & $100(67.1)$ & $0.86(0.36-2.06)$ & - \\
Television & $35(17.8)$ & $22(63.7)$ & $0.79(0.29-2.14)$ \\
$\quad$ Friends, teachers and others & $12(6.1)$ & $7(61.7)$ & \\
Total & - & $129(66.2)$ & \\
\hline
\end{tabular}

${ }^{\mathrm{a}}$ No education: 5; Primary 22; ${ }^{\mathrm{b}}$ Buddhist: 28; Christian: 5; Kirat: 2; Islam: 1; ${ }^{\mathrm{C} B o y / g i r l f r i e n d: ~ 34, ~ C a u s a l ~ p a r t n e r: ~} 3$; Ref: Reference category; ${ }^{*} P<0.05$

protect against unintended pregnancy and sexually transmitted infections.

The use of one of the modern contraceptive methods at first sexual encounter was, in univariate analysis, significantly associated with young people's sex, schooling, age at first sexual encounter and relationship type. However, in the multivariate analysis only age at first sexual intercourse and relationship type with a partner was statistically significantly associated with modern contraceptive use. Although it was expected that socio-cultural factors such as religion and ethnicity might influence the use of modern contraceptive use among youth, however, it did not have any significant association with use of contraception at first sexual relationship.

In contrast use of a modern method of contraception was associated with religion with significantly less odds of using a modern method of contraception if the young person identified as Hindu. Other studies have similarly reported that socio-cultural factors such as religion influence sexual attitudes and behaviour including utilisation of contraception [13, 29-32]. The possible reason for greater use of contraception by non-Hindu youths, primarily Buddhist and Christian, may relate to the more egalitarian nature of their religious and cultural beliefs and practices compared to the Hindu mores [32]. Studies have shown that there is a strong preference for childbearing immediately after marriage in Hindu societies to demonstrate that the partnership is a good one and women may not be educated about contraceptive options until after the birth of the first child [33, 34].

Although not demonstrated in our study, other research in Nepal and elsewhere has consistently shown that young people with higher education are more likely to use contraception than those who have little or no education [13, 17]. Reasons for our finding are possibly due to the sample, who were an urban population and who were likely to be aware of contraception and its benefits though exposure to mass media. This sample also excluded young women wishing to conceive who were likely to be less educated as they had chosen marriage and childbirth over tertiary studies.

Several limitations of the study should be noted. Young people provided information about their sexual relationship and contraceptive use retrospectively and there is the possibility that recall bias, social desirability and underreporting affected their responses. Another limitation of this study concerns the sample of participants. This study is limited to sexually active young people living in urban areas of the Kathmandu valley, and therefore, the generalizability of this study's findings is restricted. The responses to the question on use of contraceptives are self-reported and the validity of the respondents' claims has not been ascertained. However, the study team made a concerted effort to improve the reliability of the data by undertaking the interviews in total privacy, and using validated questions.

\section{Conclusions}

This study shows that majority of youth at their first and current sexual contact used condom to protect against unintended pregnancy and sexually transmitted infections. Age at first sexual intercourse and relationship type with a partner were associated with use of modern contraceptive first sex, whereas religion was found to be associated with current modern contraceptive use. Our results present evidence that may be useful to inform future policy direction about how to increase young people's access to contraception in Nepal. In particular sex education needs to begin early as it was the youth initiating sexual intercourse under the age of 16 who were least likely to use a modern method of contraception. Young people need better skills to be able to negotiate sexual and contraceptive decisions in their relationship and the problems of high prevalence of child marriage and early childbearing that needs to be addressed if Nepal is to reach the millennium development goal in terms of gender inequality and empowerment of women. 


\section{Abbreviations}

Cl: Confidence interval; HIV: Human immuno-deficiency virus; SPSS: Statistical package for the social sciences; USA: United States of America.

\section{Acknowledgements}

We are very grateful to the young men and women who participated in this study allowing us to interview them and shared information on a sensitive subject. We thank to the Center for Research on Environment Health and Population Activities for providing technical assistance in the field in carryout data collection by mobilising their interviewers and supervisors.

\section{Funding}

No funding has been obtained from any source to carry out this study.

\section{Availability of data and materials}

"The dataset(s) supporting the conclusions of this article is (are) could be obtained from the authors on request by the editors."

\section{Authors' contributions}

LT was investigator, involved in proposal writing, designing, and recruitment and training of supervisors and data collectors, analysis and write up and in all stages of the project implementation. She did most of the analysis and write up of the draft paper. CRG contributed in the designing of project proposal, reviewing and editing drafts of the manuscript, and involved in the final approval of the paper. KM provided assistance for data analysis. KB contributed in the designing of project proposal, assisted in editing and finalising the drafts of the manuscript. All authors read and approved the final manuscript.

\section{Competing interests}

The authors declare that they have no competing interests.

\section{Consent for publication}

Written informed consent was obtained from the participants for publication of data. A copy of the written consent is available for review by the Editorin-Chief of this journal."

\section{Ethics approval and consent to participate}

Ethical clearance was obtained from the Human Research Ethics Committee of the University of Sydney and National Health Research Council in Nepal. Informed consent from each study participant was obtained after clear explanation about the purpose of the study. A written informed consent was obtained for the parents or legal guardians of participants less than 16 years.

\section{Author details}

'APS Prasuti Tatha Prajanan Swasthya Kendra, Link Marg 1045, Kuleshwor, Kathmandu, Nepal. ${ }^{2}$ School of Public Health, Faculty of Medicine, The University of Sydney, Camperdown, NSW 2006, Australia. ${ }^{3}$ Discipline of Obstetrics, Gynaecology and Neonatology, Faculty of Medicine, The University of Sydney, Camperdown, NSW 2006, Australia.

\section{Received: 8 September 2016 Accepted: 2 February 2017} Published online: 14 March 2017

\section{References}

1. Frost JJ, Lindberg LD. Reasons for using contraception: perspectives of US women seeking care at specialized family planning clinics. Contraception. 2013;87(4):465-72.

2. Cleland J, Harbison S, Shah $H$. Unmet need for contraception: issues and challenges. Stud Fam Plan. 2014;45(2):105-22.

3. Glasier A, et al. Sexual and reproductive health: a matter of life and death Lancet. 2006;368(9547):1595-607.

4. WHO. MDG 5: Improve Maternal health 2012; Available from: http://www. who.int/topics/millennium_development_goals/maternal_health/en/. Accessed 25 May 2016.

5. Patton GC, et al. Health of the world's adolescents: a synthesis of internationally comparable data. The Lancet. 2012;379(9826):1665-75.

6. GoN and UNFPA. Health related quality of life of women suffering from pelvic organ prolapse: before and 9 to 11 months after surgical interventions. Kathmandu: Ministry of Health and Population, Department of Health Services, Family Health Division and United Nations Population Fund; 2013.
7. Puri M, Cleland J. Sexual behavior and perceived risk of HIV/AIDS among young migrant factory workers in Nepal. J Adolesc Health. 2006;38(3):237-46.

8. Puri $M$, Ingham R, Matthews Z. Factors affecting abortion decisions among young couples in Nepal. J Adolesc Health. 2007;40(6):535-42.

9. Bearinger $L$, et al. Global perspectives on the sexual and reproductive health of adolescents: patterns, prevention, and potential. Lancet. 2007;369(9568):1220-31.

10. WHO. The sexual and reproductive health of young adolescents in developing countries: reviewing the evidence, identifying research gaps, and moving the agenda. Geneva: World Health Organisation; 2011.

11. Khatiwada N, et al. Sexual and reproductive health of adolescents and youth in Nepal: trends and determinants: futher analysis of the $2011 \mathrm{Nepal}$ demographic and health survey. Calverton, Maryland: Nepal Ministry of Health and Population, New ERA, and ICF International; 2013.

12. DeJong J, et al. The sexual and reproductive health of young people in the arab countries and Iran. Reprod Health Matters. 2005;13(25):49-59.

13. Dahal G, Hennink M, Hinde A. Risky sexual behaviour among young Men in Nepal, in applications and policy working paper A05/01. England: Southhampton University; 2005.

14. Puri MC, Busza J. In forests and factories: sexual behaviour among young migrant workers in Nepal. Cult Health Sex. 2004;6(2):145-58.

15. MoHP Nepal. Nepal adolescents and youth survey 2010/2011. Kathmandu: Ministry of Health and Population; 2012

16. Adhikari R, Tamang J. Premarital sexual behavior among male college students of Kathmandu, Nepal. BMC Public Health. 2009;9(1):241.

17. MoHP Nepal, New ERA, and ICF International Inc. Nepal demographic health survey 2011. Kathmandu, Nepal: Ministry of Health and Population, New ERA and ICF International Inc, Claverton, Maryland; 2012.

18. Raj $A$, McDougal $L$, Rusch MA. Changes in prevalence of girl child marriage in south asia. JAMA. 2012;307(19):2027-9.

19. Kamal Mostafa, S.M. and C.H. Hassan. Childbearing, Unintended Pregnancy and Contraceptive Use among South Asian Married Female Adolescents. 2003; Available from: http://ghf.g2hp.net/2013/08/29/childbearingunintended-pregnancy-and-contraceptive-use-among-south-asian-marriedfemale-adolescents/. Accessed 25 May 2016.

20. Leone T, Matthews Z, Zuanna GD. Impact and determinants of sex preference in Nepal. Int Fam Plan Perspect. 2003;29(2):69-75.

21. Kidsley S. Contraceptive use in Nepal. University of Southampton, School of Medicine, Doctoral Thesis. 2006. p. 21. Available from: http://eprints.soton.ac. uk/210221/1.hasCoversheetVersion/00369850.pdf. Accessed 25 May 2016.

22. Cleland J, Ingham R, Stone N. Asking young people about sexual and reproductive behaviours: illustrative core instruments. Geneva: UNDP/ UNFPA/WHO/World Bank Special Programme of Research, Development and Research Training in Human Reproduction; 2001.

23. MoHP Nepal, New ERA, and Macro International Inc. Nepal demographic health survey 2006. Kathmandu: Minsitry of Health and Population, New ERA and Macro International Inc; 2007.

24. Pulerwitz J, Barker G. Measuring attitudes towards gender norms among young men in brazil-development and pschometric evaluation of the GEM scale. Men Masculinities. 2008:10(3):322-38.

25. Pulerwitz J, Gortmaker S, DeJong W. Measuring sexual relationship power in HIV/STD research. Sex Roles. 2000:42(7):637-60.

26. Adhikari R. Factors affecting awareness of emergency contraception among college students in Kathmandu, Nepal. BMC Womens Health. 2009;9(1):27.

27. Frost JJ, Darroch JE. Factors associated with contraceptive choice and inconsistent method use, United States, 2004. Perspect Sex Reprod Health. 2008;40(2):94-104.

28. East $\mathrm{L}$, et al. Use of the male condom by heterosexual adolescents and young people: literature review. J Adv Nurs. 2007;59(2):103-10.

29. Gaydos $L$, et al. An emerging field in religion and reproductive health J Relig Health. 2010;49(4):473-84.

30. Hill NJ, Siwatu M, Robinson AK. "My religion picked My birth control": the influence of religion on contraceptive use. J Relig Health. 2014;53(3):825-33.

31. Davidson Sr JK, et al. Sexual attitudes and behavior at four universities: do region, race, and/or religion matter? Adolescence. 2008;43(170):189-220.

32. Srikanthan A, Reid RL. Religious and cultural influences on contraception. J Obstet Gynaecol Can. 2008;30(2):129-37.

33. Fisher JA, Bowman M, Thomas T. Issues for South Asian Indian patients surrounding sexuality, fertility, and childbirth in the US health care system. J Am Board Fam Pract. 2003;16(2):151-5.

34. Nath DC, Land KC, Goswami G. Effects of the status of women on the first interval in Indian urban society. J Biosoc Sci. 1999;31(01):55-69. 